\title{
Myocardial infarction with non-obstructive coronary artery disease
}

\author{
Bertil Lindahl $^{1 *}$, MD, PhD; Tomasz Baron ${ }^{1}, \mathrm{MD}, \mathrm{PhD}$; Mario Albertucci², MD; Francesco Prati ${ }^{2,3}$, MD \\ 1. Department of Medical Sciences, Uppsala University, Uppsala, Sweden; 2. Centro per la Lotta contro l'Infarto (CLI) \\ Foundation, Rome, Italy; 3. Uni-Camillus, Saint Camillus International University of Health Sciences, Rome, Italy
}

\section{KEYWORDS \\ - clinical research \\ - miscellaneous \\ - risk stratification}

\section{Abstract}

As a result of the increased use of coronary angiography in acute myocardial infarction in the last two decades, myocardial infarction with non-obstructive coronary arteries (MINOCA) has received growing attention in everyday clinical practice. At the same time, research interest in MINOCA has increased significantly. MINOCA is a heterogeneous disease entity seen in $5-10 \%$ of all patients with myocardial infarction, especially in women. Clinically, MINOCA may be difficult to distinguish from other non-ischaemic conditions that can cause similar symptoms and myocardial injury. There is still some confusion around the diagnosis, investigation and management of patients with MINOCA. The present review summarises the current knowledge of MINOCA regarding epidemiology, pathophysiology, investigation, and treatment, with a special focus on imaging modalities. In addition, remaining important knowledge gaps are highlighted. 


\section{Abbreviations}

ACEI angiotensin-converting enzyme inhibitors

ACS acute coronary syndromes

ARB angiotensin receptor blockers

CAD coronary artery disease

CMD coronary microvascular disease

CMR cardiac magnetic resonance imaging

CT computed tomography

CTCA computed tomography coronary angiography

DAPT dual antiplatelet treatment

IVUS intravascular ultrasound

MACE major adverse cardiac events

MI myocardial infarction

MI-CAD myocardial infarction - coronary artery disease with significant stenosis

MINOCA myocardial infarction with non-obstructive coronary arteries

OCT optical coherence tomography

PCI percutaneous coronary intervention

PET positron emission tomography

SCAD spontaneous coronary artery dissection

\section{Introduction}

The first paper including the term "myocardial infarction with nonobstructive coronary arteries" (MINOCA) was published in 2013; by the end of 2020, 210 papers had been published. Although it has been known for a long time that myocardial infarction (MI) might occur in the absence of obstructive coronary artery disease $(\mathrm{CAD})^{1}$, awareness of and interest in the phenomenon among clinicians only gained momentum as coronary angiography became common in the management of acute MI. Although knowledge about MINOCA is rapidly increasing, there are still fundamental gaps in our current knowledge. Furthermore, there is also some confusion and lack of consensus regarding the definition of MINOCA, which is important to bear in mind when interpreting the literature.

\section{DEFINITION OF MINOCA}

Myocardial infarction is defined pathologically as myocardial cell death due to prolonged ischaemia. Clinically, elevation of troponin is used as a surrogate for myocardial cell death and, hence, all myocardial injury detected by elevated troponin in the setting of acute myocardial ischaemia should be labelled as $\mathrm{MI}^{2}$. For the diagnosis of MINOCA, the fourth universal definition of myocardial infarction (UDMI) requires that the usual criteria for MI are met and, in addition, no stenosis $\geq 50 \%$ in a major epicardial artery is demonstrated on coronary angiography (i.e., non-obstructive coronary arteries) ${ }^{2}$. The cut-off of $50 \%$ diameter stenosis for defining "obstructive CAD" in MINOCA is based on studies on what degree of stenosis is flow limiting and may cause ischaemia under stress ${ }^{3}$. MINOCA may be further subdivided into no or very minor atherosclerosis (0-30\% stenosis) and minor atherosclerosis with 30-49\% stenosis ${ }^{4}$.

In theory, the diagnosis of MINOCA is clearly separated from MI with obstructive CAD (MI-CAD) as well from myocardial injury of non-ischaemic causes, e.g., Takotsubo syndrome and myocarditis (Central illustration, part A). However, in the real world, due to the lack of specificity of ischaemic symptoms, ischaemic electrocardiogram (ECG) changes and difficulty in measuring the exact degree of stenosis on coronary angiography, the situation is much less clear (Central illustration, part B). Therefore, the European Society of Cardiology (ESC) position paper added a third criterion for the diagnosis of MINOCA: no clinically overt specific cause for the acute presentation other than AMI. Nevertheless, it can be very difficult to exclude other conditions, mainly myocarditis or Takotsubo syndrome, from MINOCA on the basis of the clinical presentation ${ }^{5}$. Therefore, the initial diagnosis of MINOCA should be considered as a working diagnosis until other causes of the clinical presentation are excluded, preferably by early cardiac magnetic resonance (CMR) imaging ${ }^{4}$. How to distinguish MINOCA from these two conditions is discussed in more detail below.

Patients with MINOCA can present themselves with a variation of ECG findings ranging from ST-segment elevation or depression to T-wave inversion or no pathological ECG changes. Hence,
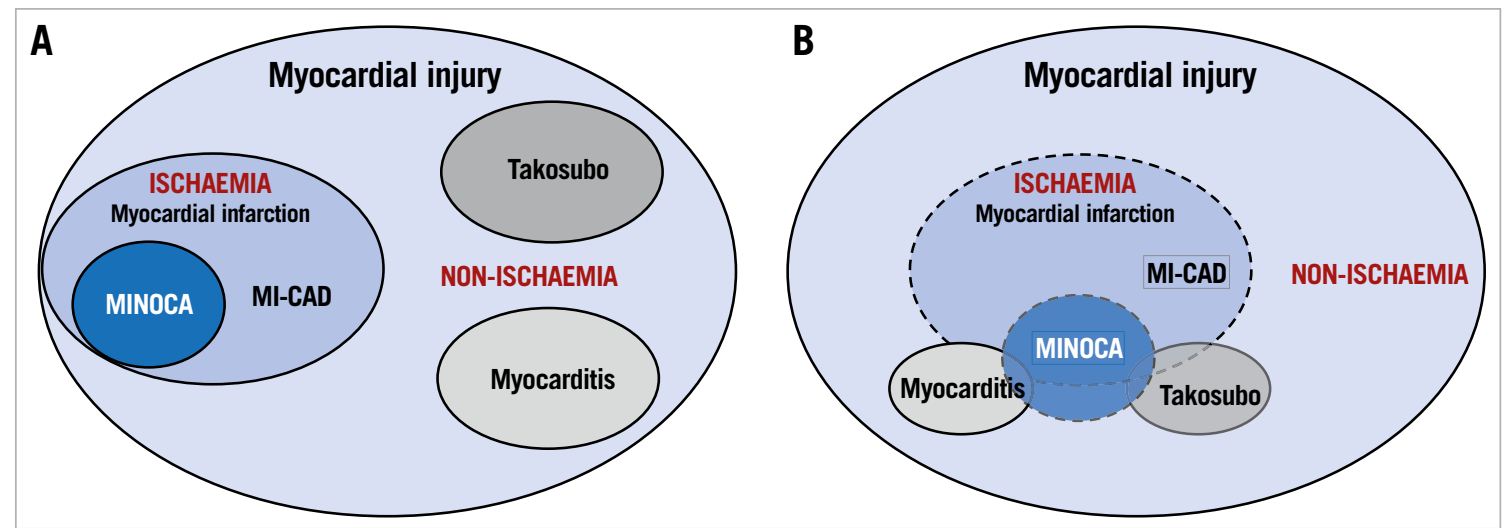

Central illustration. Schematic illustration of different conditions that cause myocardial injury, based on whether there is an ischaemic or non-ischaemic cause of the injury. A) In theory, ischaemic and non-ischaemic conditions are clearly separated. B) In clinical practice, the delimitation of the different conditions is sometimes unclear and difficult to determine. 
MINOCA patients can be classified as ST-segment elevation myocardial infarction (STEMI) or non-ST-segment elevation myocardial infarction (NSTEMI) and meet the type 1 or type $2 \mathrm{MI}$ definitions (Figure 1).

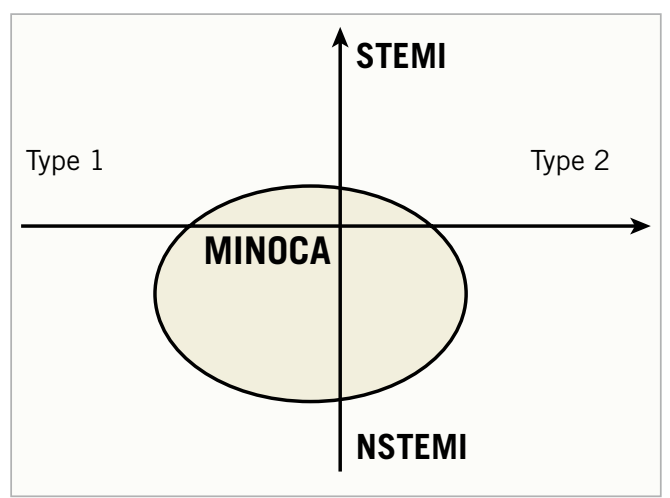

Figure 1. Schematic illustration of the relation between myocardial infarction with non-obstructive coronary arteries (MINOCA) and ST-elevation myocardial infarction (STEMI)/non-ST-elevation myocardial infarction (NSTEMI) and type 1 myocardial infarction (MI)/type 2 MI, respectively.

\section{EPIDEMIOLOGY AND PROGNOSIS}

MINOCA is relatively common, a meta-analysis of 28 studies from 1995 to 2013 found that MINOCA accounts for $6 \%$ of all MIs $^{6}$. In sharp contrast to MI-CAD, females are more common than men among MINOCA patients, in most studies $>50 \%$ are women ${ }^{7}$. Some, but not all, studies have indicated that MINOCA patients are slightly younger than MI-CAD patients ${ }^{6}$. Compared to patients with MI-CAD, MINOCA patients have fewer traditional risk factors and previous or concomitant cardiovascular diseases, except for hypertension, which seems to be equally common among MINOCA and MI-CAD patients,

Patients with MINOCA were initially considered to have a benign prognosis. However, larger long-term studies have shown that the prognosis is not benign, with an increased risk of death and new cardiovascular events. A recent meta-analysis of 44 studies showed an annual mortality rate of $2.0 \%{ }^{8}$. Other studies have shown an increased risk of a new MI (in the majority a new MINOCA) and hospitalisation for heart failure and stroke ${ }^{7,9}$. The maximal level of cardiac troponin during the MINOCA event is associated with long-term mortality ${ }^{10}$.

\section{DIAGNOSTIC STRATEGY IN MINOCA}

The 2019 scientific statement on MINOCA from the American Heart Association introduced a three-step diagnostic strategy in patients with an initial working diagnosis of MINOCA ${ }^{4}$.

Step 1. Consider the clinical context and exclude different clinical diagnoses, among others, pulmonary embolism and sepsis.

Step 2. Exclude that a true MI-CAD has been missed by re-evaluating the coronary angiogram for missed significant stenosis or side branch occlusion. Exclude other possible non-ischaemic causes of the clinical presentation and the troponin elevation, such as myocarditis and Takotsubo syndrome, by an early CMR examination.

Step 3. Determine the underlying cause of MINOCA, if possible.

If alternative causes for the clinical presentation and myocardial injury are excluded in step 1 and 2, a diagnosis of "true" MINOCA can be made. The second and third steps are described in more detail below.

\section{DIFFERENTIATION OF MINOCA FROM NON-ISCHAEMIC CAUSES OF MYOCARDIAL INJURY IN PATIENTS WITH NO OR NON-OBSTRUCTIVE CAD (STEP 2)}

As previously mentioned, sometimes it can be very difficult to exclude other conditions mimicking MINOCA based on the clinical presentation. This is particularly true for Takotsubo syndrome and myocarditis. Typical cases of Takotsubo syndrome can be identified on a left ventricular angiogram and/or an ECG, investigations that should always be performed early in patients with suspected MINOCA. However, for diagnosis of more subtle cases of Takotsubo syndrome or myocarditis, CMR is the method of choice and is recommended routinely in patients with suspected $\mathrm{MINOCA}^{4}$. The prevalence of Takotsubo syndrome and myocarditis in patients with a working diagnosis of MINOCA examined with CMR varies widely in the literature, between $2 \%-27 \%$ and $7 \%-63 \%$, respectively ${ }^{6,11-16}$. The wide variation is dependent on how the study cohort was selected, the timing of the CMR examination, and the choice of CMR technique and diagnostic criteria.

Late gadolinium enhancement (LGE) on CMR enables assessment of the localisation and size of the infarct in MINOCA. However, in a substantial proportion of patients (8\%-73\%) fulfilling the diagnostic criteria for MINOCA, and in whom myocarditis or Takotsubo syndrome is ruled out by CMR, it is not possible to demonstrate a localised area of infarction by LGE ${ }^{6,11-16}$. Using contemporary LGE sequences with an average voxel size of $1.4 \times 1.8 \times 6(-8) \mathrm{mm}$, at least $0.2 \mathrm{~g}$ of infarcted myocardium is required to be detectable by $\mathrm{LGE}^{17}$. The amount of infarcted myocardium required to result in small but significant increases in the concentration of cardiac troponin is much less than $0.2 \mathrm{~g}^{18}$, which may explain why many patients with MINOCA do not show areas of infarction on CMR. However, the possibility that there are causes for the elevation of troponin other than ischaemic necrosis in some of these patients cannot be ruled out.

\section{CMR TECHNIQUES}

Standard CMR imaging protocols enable evaluation of cardiac anatomy and function (steady-state free precession [SSFP] magnetic resonance imaging [MRI] or cine images) as well as tissue characteristics. T2-weighted sequences without (T2w) and with fat suppression (T2wSTIR) enable detection of localised oedema, while T1-weighted sequences after gadolinium contrast injection (LGE) permit detection of a localised acute cellular membrane damage and/or a chronic myocardial fibrosis/scar. The extent of LGE allows differentiation between MI and myocarditis with typical subendocardial/transmural (Figure 2A) and subepicardial/ 


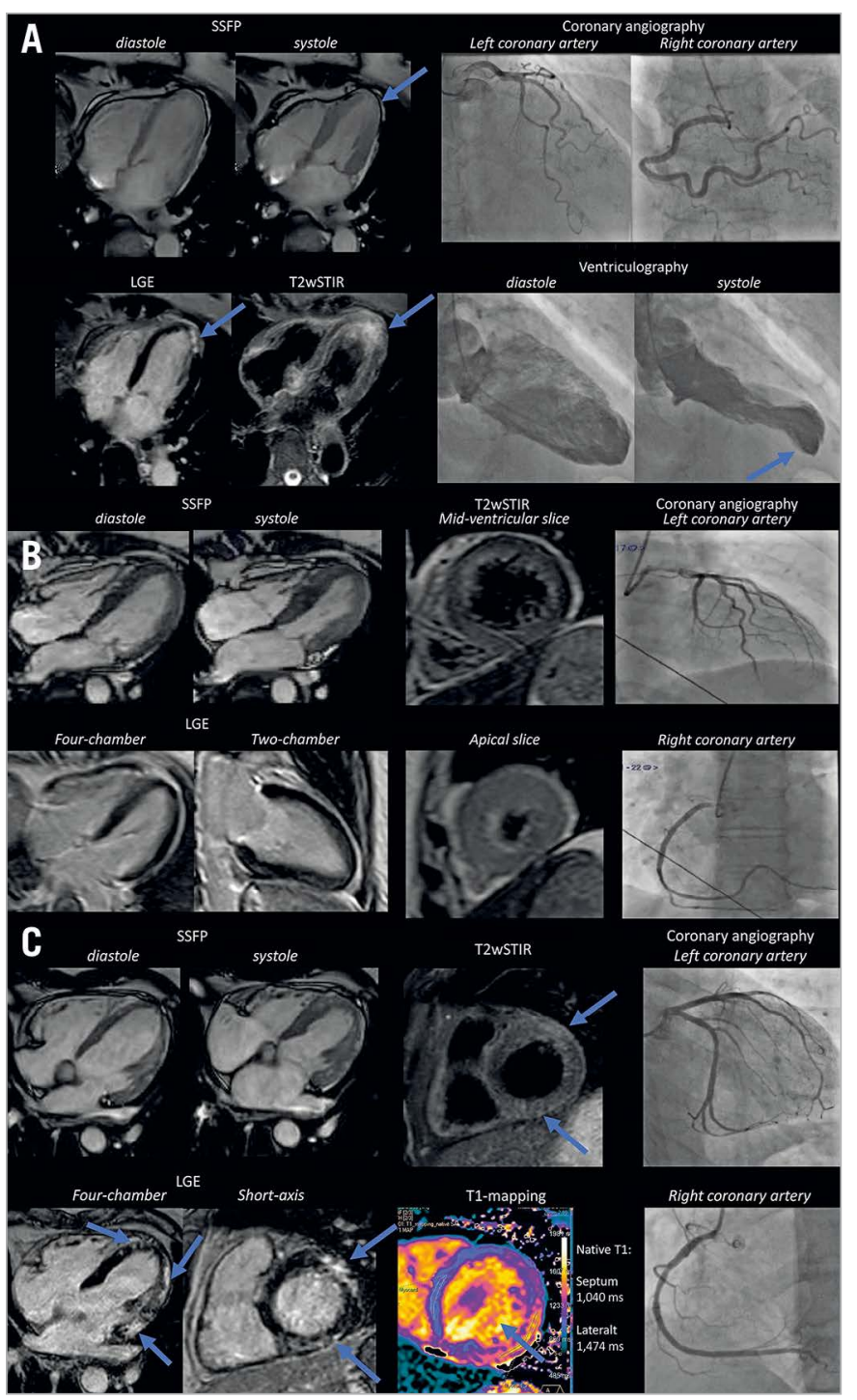

Figure 2. Examples of findings on cardiac magnetic resonance (CMR) and coronary angiography in patients with an initial working diagnosis of MINOCA. A) A 77-year-old female with hypertension, admitted due to chest pain. ECG with T-wave inversions in precordial leads. Hs-Troponin I elevation up to 8,000 ng/L. Coronary angiogram on day 1 showed non-obstructed coronary arteries. Ventriculography revealed a distal apical hypo/dyskinesia, raising suspicion of Takotsubo syndrome. CMR on day 12 showed a normal-sized left ventricle with regional akinesia limited to one apical segment of the anterolateral wall and globally normal systolic function (left ventricular end-diastolic volume [LVEDV] $64 \mathrm{ml} / \mathrm{m}^{2}$, ejection fraction [EF] 62\%) (steady-state free precession [SSFP] sequence). In the corresponding area, an increased signal in T2wSTIR sequence suggestive of oedema, and a transmural contrast enhancement in LGE sequence, suggestive of a cell membrane damage/scarring, were seen. Final diagnosis was acute myocardial infarction limited to a small area, suggestive of an embolic genesis. The apical segment with respective pathologies indicated by blue arrows. B) A 60-year-old female admitted due to acute chest pain and dizziness, with acute onset during physical activity. Ongoing hormone therapy and radiotherapy after mastectomy two months previously for breast cancer. ECG showed ST-elevations, predominantly in precordial leads. Hs-troponin elevation up to 6,300 ng/L. Coronary angiogram on day 1 showed non-obstructed coronary arteries. Ventriculography was not performed; however, echocardiography revealed an apical dyskinesia suggestive for Takotsubo syndrome. CMR on day 15 showed a normal-sized left ventricle with basal hyperkinesia and apical hypokinesia mainly in the anterolateral wall and a globally normal systolic function (LVEDV $78 \mathrm{ml} / \mathrm{m}^{2}$, EF 58\%). T2wSTIR sequence showed a clear increased oedema signal in all apical segments. No contrast enhancement was observed in LGE sequences. Final diagnosis was Takotsubo syndrome. C) A 61-year-old male without any cardiovascular risk factors admitted due to a chest pain. ECG showed generalised ST-elevations. Acute coronary angiogram showed non-obstructed coronary arteries. Hs-Troponin I elevation up to $>50,000 \mathrm{ng} / \mathrm{L}$. CMR on day 4 revealed a normal-sized left ventricle with regional hypokinesia in mid-apical lateral wall and in mid anterior wall and globally mildly impaired systolic function (LVEDV $89 \mathrm{ml} / \mathrm{m}^{2}$, EF 51\%) (SSFP sequence). Oedema sequences (T2wSTIR) showed an increased signal in the entire anterolateral wall and in basal-midventricular inferior wall, which also could be confirmed by prolonged native T1-time in T1-mapping sequence. Viability sequences (LGE) show widespread subepicardial and mid-wall signal increase throughout the anterolateral wall, in basal inferior wall, and mid-wall in apical septum. The pattern was suggestive of acute myocarditis. 
mid-wall pattern (Figure 2B), respectively. Typical Takotsubo syndrome presents with an apical and mid-ventricular oedema concomitant with a transient dyskinesia, commonly in the apical and mid-ventricular segments and a hyperkinesia in the basal segments, without any LGE (Figure 2C).

Some newer MRI techniques can improve diagnostic precision. Use of parametric T1-mapping with calculation of an extracellular volume (ECV), as well as T2-mapping sequences, permits a quantitative pixel-by-pixel determination of tissue features, both extracellular and intracellular, related to the amount of water in myocardial tissue (e.g., inflammation and oedema). It can also identify diffuse changes, such as generalised fibrosis, which LGE cannot visualise. The recently published updated Lake Louise Criteria for CMR in myocardial inflammation introduced mapping sequences and redefined imaging diagnosis according to the combined presence of a T1 criterion (presence of LGE or increased T1-mapping or extracellular volume values) and a T2 criterion (hyperintensity in T2wSTIR or increased T2-mapping values) ${ }^{19}$. Implementation of mapping techniques has improved the diagnostic performance of CMR for the diagnosis of acute myocarditis, in particular in atypical clinical presentation ${ }^{20}$.

Recently introduced new free-breathing LGE techniques have substantially improved spatial resolution (up to five times) and permit detection of a smaller amount of necrosis. In a recently published study, by adding this new sequence to the standard imaging protocol, a final diagnosis could be obtained in $48 \%$ of MINOCA patients with an initially normal $\operatorname{scan}^{21}$.

\section{TIMING OF CMR EXAMINATION}

The diagnostic precision of CMR is increased when imaging is undertaken within 7-14 days of presentation. Delayed imaging may result in certain pathological changes, such as myocardial oedema in myocarditis no longer being apparent. Dastidar et al compared results of retrospective scans in MINOCA patients, showing that early performance of CMR (within two weeks after admission) reduces the number of non-conclusive scans from $43 \%$ to $16 \%$, mainly due to a better detectability of Takotsubo syndrome and myocarditis ${ }^{22}$. In serial scans of patients with a working diagnosis of MINOCA, in whom early scans revealed myocarditis, scans more than three weeks after admission showed a complete resolution of epicardial LGE pattern in one fourth ${ }^{23}$.

\section{DETERMINATION OF THE PATHOPHYSIOLOGICAL MECHANISMS IN MINOCA (STEP 3)}

Coronary angiography is key for the diagnosis of MINOCA. However, coronary angiography has certain limitations for determining its pathophysiology. Angiographically, culprit plaques may seem normal, although there may be findings compatible with MINOCA. These include mild narrowing (less than 50\%), lesions with asymmetry, narrow neck, irregular borders, haziness or radiolucent flap $^{5,24,25}$. Techniques for measuring the functional significance of an epicardial coronary stenosis, such as fractional flow reserve (FFR), are increasingly used. FFR reveals the specific ischaemic potential of the stenosis ${ }^{26}$. Intracoronary imaging by means of optical coherence tomography (OCT) or intravascular ultrasound (IVUS) offers additional information in terms of the pathophysiology and was therefore recommended in a recent consensus document when diagnostic or angiographic uncertainty exists ${ }^{27}$.

The underlying pathophysiological mechanisms in MINOCA are still poorly understood. Several different mechanisms for the development of MINOCA have been proposed. Although not mutually exclusive, they can be divided into the following four categories.

1. Processes in the epicardial coronary vessels. This category includes rupture/fissure of small non-significant atherosclerotic plaques, spontaneous coronary artery dissection (SCAD), epicardial vasospasm and in situ thrombosis. Plaque rupture/ endothelial erosion are probably quite common causes of MINOCA (Figure 3A); they are dealt with in more detail below. SCAD is an uncommon cause of MINOCA except in younger women $^{28}$; it is also dealt with in more detail below. Spasm of an epicardial coronary artery may cause transient ischaemia and, in some cases, may even lead to persistent ischaemia, which can cause MINOCA. The diagnostic criteria for coronary spasm have been addressed by the Coronary Vasomotion Disorders International Study Group (COVADIS) ${ }^{29,30}$. The frequency of epicardial yasospasm as the cause of MINOCA is dependent on the definition of coronary spasm and the cohorts studied. It varies very widely in different studies, ranging from $3 \%$ to $95 \%{ }^{31,32}$. Provocative tests for spasm are seldom used in clinical practice in most countries; however, some recent studies have shown the procedure to be safe ${ }^{33}$. Recently, Reynolds et al identified on OCT a new feature possibly related to vasospasm - superficial bumps ${ }^{34}$. This finding was reported in $2.1 \%$ of patients with MINOCA. In situ thrombosis associated with coagulation disorders and extracardiac embolus are rare causes of MINOCA.

2. Coronary microvascular disease (CMD). CMD is thought to be a common cause of MINOCA. It is discussed in more detail below.

3. Increased oxygen demand and/or decreased oxygen supply. Increased oxygen demand and/or decreased oxygen supply may lead to myocardial ischaemia and necrosis, i.e., type $2 \mathrm{MI}^{2}$. Studies have shown that approximately half of the patients with type $2 \mathrm{MI}$ do not have significant $\mathrm{CAD}$, i.e., can be classified as having $\mathrm{MINOCA}^{35}$. The prevalence of type $2 \mathrm{MI}$ is heavily dependent on the studied population. Frequencies of type $2 \mathrm{MI}$ ranging from $2 \%$ to $30 \%$ of the total numbers of MI have been reported $^{36}$. IVUS and OCT can be helpful to define the presence of mild non-significant coronary narrowing that may contribute to secondary ischaemia triggered by arrhythmias, marked anaemia, or respiratory disease ${ }^{27}$ (Figure 3B). This mechanism of coronary ischaemia is relatively common in aged people, particularly in the presence of left ventricular hypertrophy.

4. Unknown mechanisms. In a significant proportion of patients with MINOCA the underlying mechanism cannot be firmly 

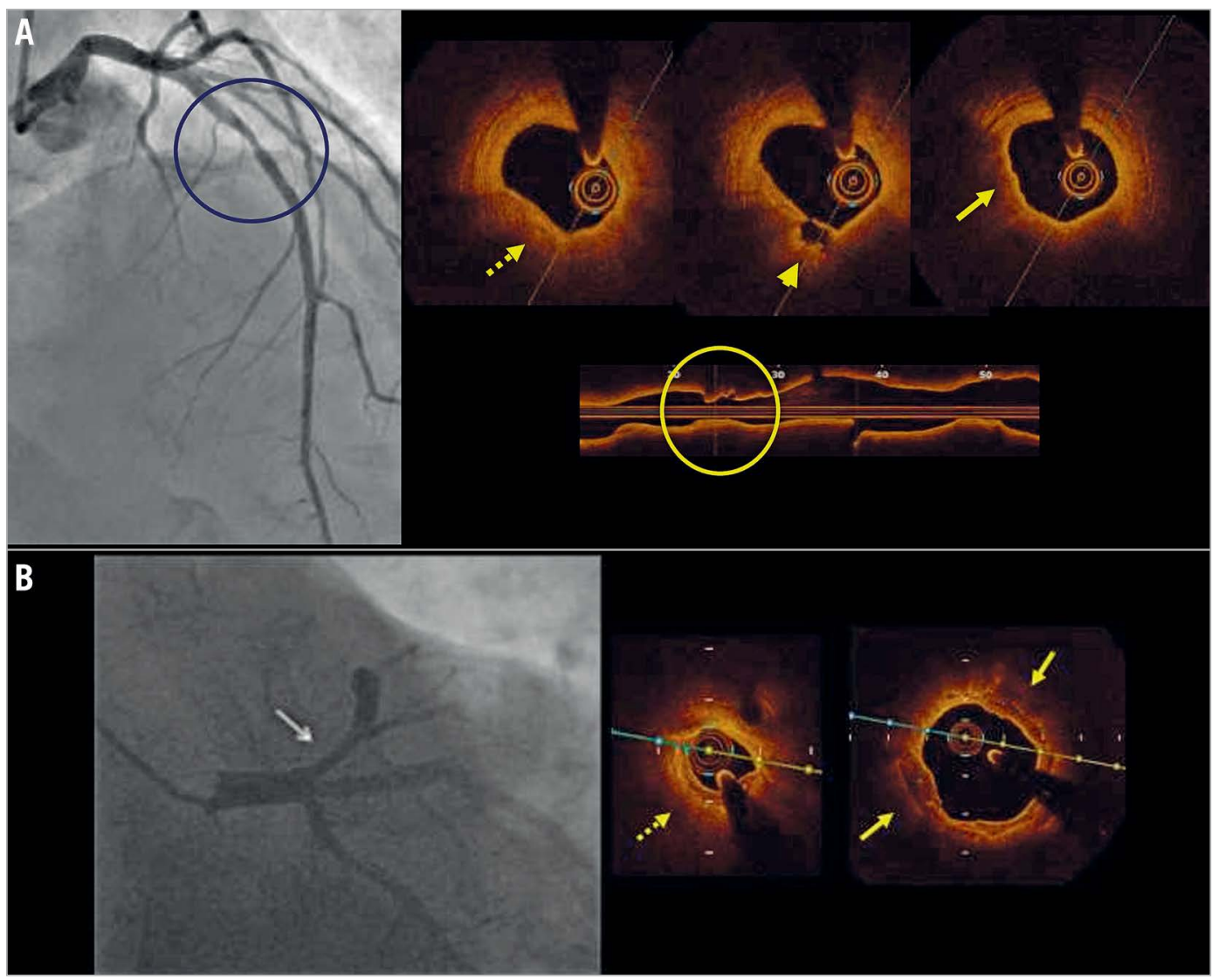

Figure 3. Examples of findings at coronary angiography and OCT imaging in MINOCA. A) A patient admitted with chest pain and anterior ST depression on ECG. Angiography (left panel) shows an intermediate narrowing in the mid left anterior descending artery. OCT showed an atherosclerotic plaque with thin fibrous cap (dotted arrow), a small fibrous cap ulceration (arrowhead) and minimal luminal irregularities due to thrombus remnant (solid arrow). The OCT longitudinal view shows the plaque architecture and plaque ulceration. The findings on OCT confirm the diagnosis of MINOCA. B) A patient admitted to the chest unit for a hypertensive crisis with concomitant anterior ST depression on ECG. Angiography shows an intermediate narrowing in the proximal left anterior descending artery (arrow in the left panel). OCT shows an atherosclerotic plaque with calcific components (solid arrow) in the reference cross sections. At the most narrowed site a small lumen area (less than $3.0 \mathrm{~mm}^{2}$ ) is present (dotted arrow). The findings on OCT are compatible with a diagnosis of MINOCA due to oxygen supply-demand mismatch (secondary ischaemia).

established, even after extensive investigations. There are probably still unknown mechanisms behind some cases of MINOCA. Furthermore, in some patients there might be an overlap with mild forms of Takotsubo syndrome, not detectable with current methods.

\section{PLAQUE RUPTURE OR EROSION}

MINOCA is caused by atherosclerotic plaque ulceration with superimposed thrombus (plaque ulceration) or by acute thrombosis in the presence of an intact fibrous cap (plaque erosion) in a significant number of cases ${ }^{5}$. However, MINOCA often shows only small thrombus remnants because of endogenous partial thrombolysis and/or the use of anticoagulant-antiplatelet drugs ${ }^{27}$. In this regard OCT, with its high resolution in the range of 10-20 microns, is the modality with the most potential ${ }^{27,37}$. However, some thrombus can obscure the underlying vessel wall imaged with OCT because of its high signal attenuation ${ }^{27,37}$. The aspect of thrombus on OCT changes over time. The irregular inner border of the thrombus in the acute phase evolves to a homogeneous and smooth profile in the following weeks ${ }^{38}$. IVUS detection of thrombus is more challenging ${ }^{37,39,40}$. Stationary imaging at the level of the culprit plaque can be improved by means of a small injection of contrast to highlight the luminal contour. High-definition IVUS has, however, better diagnostic capabilities ${ }^{27}$.

Plaque rupture is found in about $60-70 \%$ of cases of acute coronary syndrome (ACS) $)^{2,41}$ and is also relatively common in MINOCA. Plaque rupture is well recognised by OCT as a discontinuity of the fibrous cap overlying a lipid-rich core that typically occurs with overlying thrombosis. Occasionally, an ulcerated lesion without thrombus may be the cause of MINOCA (Figure 3A). In such cases it may be assumed that local thrombosis responsible for the myocardial injury has been completely cleared or migrated into the periphery. Reynolds et al found layered plaques in $13.1 \%$ of patients with MINOCA $^{34}$. As layered plaques are related to an old plaque healing process ${ }^{38}$, another underlying mechanism explaining the acute event should be considered in such cases. 
IVUS is also able to identify ruptured plaques. However, because of its lower resolution, IVUS provides less clear-cut images of superficial plaque components ${ }^{27}$. As a main advantage IVUS has better penetration than OCT and can study the outer plaque layers, providing information on lipid content and vessel remodelling $37,39,40,42$. Near infrared spectroscopy (NIRS)-IVUS imaging provides information about the cholesterol content in the arterial wall, detailing a component of plaque vulnerability ${ }^{43,44}$. In MINOCA, culprit plaques with ulcerations tend to have large lipid components.

Approximately one third of patients with MINOCA have plaque disruption on IVUS ${ }^{45}$. Reynolds et al studied 42 women with MINOCA using IVUS, plaque disruption was observed in $16 / 42$ patients $(38 \%)^{45}$. Of these, 12 patients had plaque rupture and 4 had only plaque ulceration. These data are consistent with those provided by Hong et al, who performed a three-vessel IVUS study in patients with ACS or stable angina pectoris ${ }^{46}$. Plaque ruptures were found in $68 \%$ and $30 \%$ of patients with ACS and stable angina, respectively. Of note, the authors in these studies did not attempt to visualise thrombus with IVUS.

Similar proportions of MINOCA patients with plaque disruption are found in studies using OCT and CMR: Gerbaud et al found plaque rupture in $35 \%$, Opolski et al in $40 \%$, Reynolds et al in $29 \%$, and Taruya et al in $16 \%$ of cases ${ }^{12,34,47,48}$.

Plaque erosion may also be a common cause of MINOCA. Thrombosis without ulceration was found in 30\% of cases on OCT by Gerboud et al, and in $50 \%$ of cases by Opolski et al ${ }^{12,34,47}$. However, Reynolds et al found lone thrombus in only $3.5 \%$ of cases and Taruya et al found lone thrombus in $8.5 \%$ and plaque erosion in $1.2 \%$ of cases $^{34,47,48}$.

Calcified nodules are an infrequent cause of acute thrombosis in ACS (about $5-6 \%$ of ACS). They typically occur in aged atherosclerosis and seem unlikely to be involved in MINOCA. In fact, no study has found calcified nodules in MINOCA patients, except Taruya et al, who found calcified nodules in $11.0 \%$ of the patients $^{12,34,47,48}$.

Examination with OCT may also be useful for prognostic purposes. Prati et al found that the simultaneous presence of four high-risk OCT plaque features was associated with a higher risk of major coronary events in patients with a clinical indication to coronary angiography undergoing OCT evaluation of the left anterior descending artery, regardless of the clinical syndrome ${ }^{49}$.

\section{SPONTANEOUS CORONARY ARTERY DISSECTION}

SCAD typically causes ACS. In the majority of cases, SCAD leads to a concomitant significant narrowing ( $>50 \%$ stenosis) and, therefore, is an uncommon cause of MINOCA ${ }^{5}$. SCAD typically occurs without atherosclerosis and is more common in females ${ }^{50,51}$. Several conditions or diseases have been related to SCAD, including factors making coronary wall structures more prone to dissection, or factors such as emotional stressors that may precipitate acute episodes of $\mathrm{SCAD}^{50}$. Peripartum is a predisposing condition, making SCAD the main cause of acute MI during pregnancy and the peripartum period ${ }^{52,53}$. Fibromuscular dysplasia is frequently associated with SCAD, especially when a complete screening is carried out ${ }^{54-56}$. An association also exists with collagen vascular disorders (Marfan syndrome, Ehlers-Danlos syndrome, Alport syndrome and nail-patella syndrome $)^{57,58}$, chronic inflammatory diseases (systemic lupus erythematosus, inflammatory bowel disease and sarcoidosis $)^{59-62}$, and periadventitial eosinophils infiltrate ${ }^{63}$.

SCAD is characterised by the development of a false lumen within the coronary artery wall that may compress the true lumen and cause ischaemia ${ }^{5,64}$. Two mechanisms have been proposed to explain the development of the false lumen in $\mathrm{SCAD}^{65,66}$. The first one is the so-called "inside-out" hypothesis, the cause resides in the disruption of the endothelial-intimal layer, which allows blood from the lumen to enter the vessel wall, leading to the formation of an intramural haematoma. According to a second "outsidein" hypothesis, the primary event is a bleeding of the vasa vasorum that leads to intramural haematoma in the absence of intimal disruption. In both scenarios, haematoma can progress and lead to the compression of the true lumen, resulting in myocardial ischaemia ${ }^{66,67}$. On a positive note, SCADs often heal spontaneously. Observational studies have shown angiographic "healing" of SCAD lesions in a large percentage of cases, between $70 \%$ and $97 \%{ }^{68,69}$. Healing tends to occur in an early phase (within days) and is a common finding after the first month ${ }^{50,70}$.

In general, coronary angiography is the key diagnostic tool ${ }^{50,70}$. Although angiography does not enable imaging of the arterial wall, it portrays unique disease aspects of SCAD. Based on the angiographic pattern, three types of SCAD can be identified (Figure 4). Type 1 lesions are defined by the presence of a double lumen image, Type 2 lesions by the presence of a long lumen narrowing, usually with a length over $20 \mathrm{~mm}$. Two subtypes of SCAD type 2 have been identified: type $2 \mathrm{a}$, when the distal vessel recovers the normal size; and type $2 b$, when the intramural haematoma extends distally to the end of the coronary artery. Lastly, type 3 lesions, which are defined by an abrupt focal narrowing (lesion length $<20 \mathrm{~mm}$ ) therefore mimicking an atherosclerotic lesion ${ }^{28,50,51,67}$. In the SCAD registry by Saw et al, the most commonly observed angiographic appearance was type $2(67.0 \%$ of cases), with type 1 occurring in $29.1 \%$ and type 3 in $3.9 \% 0^{50}$. There were no differences in the baseline characteristics or clinical outcomes according to the angiographic subtypes.

At present, computed tomography coronary angiography (CTCA) use has important limitations for diagnosing SCAD. In the presence of SCAD, CTCA can reveal an abrupt luminal narrowing, followed by intimal media haematoma identification. Unfortunately, CTCA sensitivity is suboptimal because of its poor spatial resolution; therefore, it does not seem suited for identifying distal or mild lesions ${ }^{71}$.

Use of other imaging modalities for a correct diagnosis of SCAD is often superfluous. In the presence of type 1 and type 2 SCAD, angiography plus clinical and demographic variables are largely sufficient to make a correct diagnosis. However, both IVUS and OCT are helpful in type 3 dissections that have 


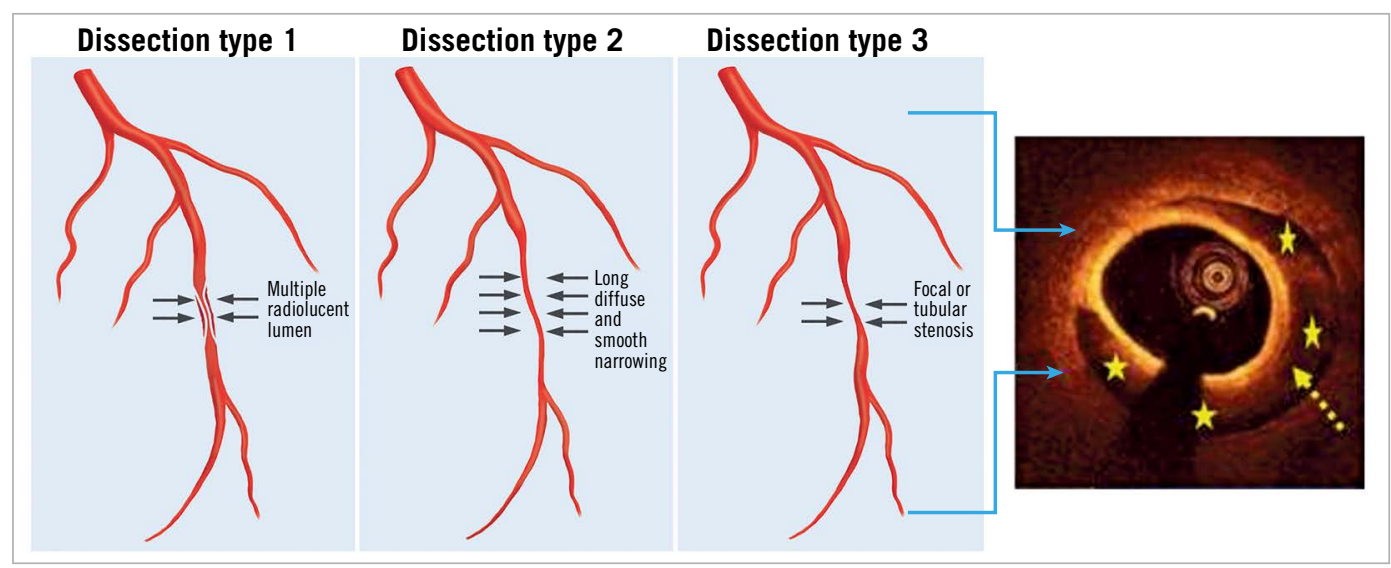

Figure 4. Three types of SCAD. Left panels. Schematic figure of the three different types of dissections. Reprinted with permission from ${ }^{55}$. Right panel: OCT image illustrating a type 3 dissection with vessel haematoma (asterisks) and the presence of the inner three vessel layer at the site of dissection (dotted arrow).

angiographic features that resemble those of atherosclerotic lesions (Figure 4). OCT may identify the rupture site (the entry tear), visualise the intima-medial membrane and comprehensively assess its characteristics, and the extent and distribution of the true and false lumen/intramural haematoma ${ }^{67}$. IVUS has two advantages over OCT: it has greater penetration, showing the entire intramural haematoma, and is perhaps safer as it does not require contrast injection. However, this is at the expense of a lower anatomical definition. The visualisation of localised fenestrations, intimal flaps or true luminal thrombus do not seem possible with IVUS.

The benefits of intracoronary imaging modalities should be balanced against the potential complications caused by vessel instrumentation, insertion of intracoronary catheters may lead to propagation of dissection ${ }^{72}$. Compared to IVUS, OCT has adjunctive limitations. The necessity of contrast injection, might potentially further expand the dissection by hydraulic pressure.

A computed tomography (CT) scan is extremely helpful for identifying extra-coronary vascular abnormalities, including fibromuscular dysplasia. According to Liang et al, comprehensive CT protocol identified fibromuscular dysplasia in $69 \%$ of patients with $\mathrm{SCAD}^{73}$. The US Registry for Fibromuscular Dysplasia showed that the most commonly involved vascular beds are the renal (79.7\%), followed by the extracranial carotid arteries $(74.3 \%)^{74,75}$. Intracranial aneurysm was reported in $14 \%$ to $23 \%$ of cases ${ }^{50,73}$.

\section{CORONARY MICROVASCULAR DISEASE}

The coronary microcirculation has a fundamental role in the regulation of coronary blood flow in response to cardiac oxygen requirements. Myocardial oxygen extraction is almost maximal at rest in the heart. Therefore, an increase in oxygen demand must be matched by a corresponding increase in coronary blood flow. Coronary microvascular disease (CMD) hampers the necessary increase in coronary flow in response to increased oxygen demand and may lead to myocardial ischaemia.
Nearly one half of patients with stable chest pain undergoing coronary angiography do not show obstructive coronary lesions. A substantial proportion of these patients present abnormalities in the function and structure of the coronary microcirculation due to endothelial and smooth muscle cell dysfunction, defined as CMD. Among consecutive emergency room (ER) chest pain patients without evidence of MI or CAD, $42 \%$ had signs of CMD on $\mathrm{Rb} 82$ cardiac positron emission tomography (PET)/CT, 36\% had CAD and $22 \%$ normal flows ${ }^{76}$. CMD is strongly associated with the development of heart failure with preserved ejection fraction, diabetes, hypertensive heart disease, and carries an increased risk of adverse cardiovascular clinical outcomes ${ }^{77}$.

Microvascular dysfunction is considered to be a potential cause of $\mathrm{MINOCA}^{4}$, even although not extensively studied as in stable chest pain patients. It is has been estimated that CMD, expressed by coronary microvascular spasm, accounts for about $20 \%$ of MINOCA patients ${ }^{5,6}$. CMD can cause ischaemia, but it can also be a consequence of myocardial injury of either ischaemic or nonischaemic origin. Using stress CMR, an abnormal stress perfusion was found in $63 \%$ women with MINOCA and was associated with myocardial oedema, but the abnormal stress perfusion matched with a myocardial scar in only $75 \%$ of cases $^{78}$. The precise contribution of CMD in MINOCA requires additional studies in order to assess the roles of microvascular angina, microvascular spasm, and the coronary slow flow phenomenon.

Diagnosis of CMD is usually based on functional assessment of the microcirculation, which can be performed by both invasive and non-invasive methods. Invasively, both microvascular vasodilatation (measured by coronary flow reserve and index of microvascular resistance) and microvascular spasm (induced by intracoronary acetylcholine infusion) can be measured. Although being the reference standard for the diagnosis of CMD, the invasive tests of coronary artery function are not widely used in clinical practice, due to their time-consuming complexity and, at many sites, a lack of clinical experience. Non-invasively, myocardial perfusion can be assessed 
by PET and CMR. PET is the reference standard for non-invasive assessment of myocardial blood flow and coronary flow reserve, calculated as the ratio of myocardial blood flow during pharmacologically induced maximal hyperaemia and at rest ${ }^{79}$. Its availability, cost and exposure to radiation are limiting factors for a wide use of PET. Stress CMR are also used to assess myocardial perfusion and assessment of microcirculation. The images are acquired at rest and after vasodilator-stress (i.e., adenosine), associated with gadoliniumbased contrast agent injection ${ }^{80}$. The largest study to date comparing CMR imaging and 15O-H2O PET showed that, despite a modest agreement of myocardial blood flow and coronary flow reserve, the concordance regarding vascular territories was satisfactory ${ }^{81}$.

\section{TREATMENT OF MINOCA}

\section{MEDICAL TREATMENT}

Evidence-based treatments for MINOCA are lacking since there is no published randomised clinical trial on MINOCA, although there is one ongoing randomised clinical trial ${ }^{82}$. The treatment recommendations in current guidelines are based mainly on expert opinions. An obvious complicating factor is that MINOCA is a heterogeneous condition and, in clinical routine, the exact underlying mechanism will most often be unknown in the individual case. Furthermore, even if the likely underlying mechanism is known, appropriate treatment remains to be proven. For example, compelling evidence for a beneficial effect of dual antiplatelet therapy (DAPT) in the case of a small plaque rupture in a non-significant stenosis and without overlying thrombus is lacking.

Acute treatment purely provides symptomatic relief and there are no proven infarct size-limiting treatments in MINOCA. Except in SCAD, long-term low-dose aspirin is recommended for secondary prevention after MINOCA in recent consensus documents ${ }^{4}$. DAPT treatment is controversial, but has not been shown to be associated with lower risk in any observational study so far $^{83-87}$. A post hoc analysis of the CURRENT-OASIS 7 randomised trial comparing high dose versus standard dose of clopidogrel even indicated possible harm of high-dose clopidogrel in patients with MINOCA as opposed to in patients with MI-CAD ${ }^{88}$. In contrast, statin treatment has mostly been shown to be associated with lower mortality and a lower rate of $\mathrm{MACE}^{83-87}$, a relative decrease of the same level as was shown in randomised trials of secondary prevention with statins in MI patients ${ }^{89}$. Similarly, mostly positive results have been shown for angiotensin-converting enzyme inhibitors (ACEI) or angiotensin receptor blockers $(\mathrm{ARB})^{83-87}$. On the other hand, most studies on beta-blockers have not found significant association with outcome $^{83-87}$. In the large study of Lindahl et al, there was a non-significant trend for a beneficial effect ${ }^{83}$. For calcium channel blockers, the data are more scarce, no study has shown an association with a lower long-term risk of MACE ${ }^{84,86}$. The findings in the observational studies are summarised in Table 1. It should be noted that several of the studies are very small with low power to show significant associations. For non-pharmacological treatments, the data are even scarcer; however, one study has indicated a positive effect of physical training in MINOCA $^{90}$.
Table 1. Summary of observational studies of pharmacological secondary treatment in MINOCA.

\begin{tabular}{|c|c|c|}
\hline Drug class & Study & $\begin{array}{l}\text { Association with } \\
\text { outcome (MACE) }\end{array}$ \\
\hline \multirow{5}{*}{$\begin{array}{l}\text { Dual antiplatelet } \\
\text { therapy/P2Y } \\
\text { inhibitors }\end{array}$} & Lindahl et al ${ }^{83}$ & Non-significant \\
\hline & Kovach et $\mathrm{al}^{84}$ & Non-significant \\
\hline & Abdu et $a^{85}$ & Non-significant \\
\hline & Ciliberti G. et $\mathrm{al}^{86}$ & Non-significant \\
\hline & Paolisso P. et $a^{87}$ & Non-significant \\
\hline \multirow[t]{5}{*}{ Statins } & Lindahl et al ${ }^{83}$ & Decrease \\
\hline & Kovach et al ${ }^{84}$ & Decrease \\
\hline & Abdu et al ${ }^{85}$ & Decrease \\
\hline & Ciliberti G. et $a^{86}$ & Non-significant \\
\hline & Paolisso P. et al ${ }^{87}$ & Non-significant \\
\hline \multirow[t]{5}{*}{ Beta-blockers } & Lindahl et al ${ }^{83}$ & Non-significant \\
\hline & Kovach et al ${ }^{84}$ & Non-significant \\
\hline & Abdu et al ${ }^{85}$ & Non-significant \\
\hline & Ciliberti G. et $a^{86}$ & Decrease \\
\hline & Paolisso P. et $\mathrm{al}^{87}$ & Non-significant \\
\hline \multirow[t]{5}{*}{ ACEI/ARB } & Lindahl et $a^{83}$ & Decrease \\
\hline & Kovach et al ${ }^{84}$ & Decrease \\
\hline & Abdu FA. et al ${ }^{85}$ & Decrease \\
\hline & Ciliberti G. et al ${ }^{86}$ & Non-significant \\
\hline & Paolisso P. et al ${ }^{87}$ & Decrease \\
\hline \multirow{2}{*}{$\begin{array}{l}\text { Calcium channel } \\
\text { blockers }\end{array}$} & Kovach et al ${ }^{84}$ & Non-significant \\
\hline & Ciliberti G. et al ${ }^{86}$ & Non-significant \\
\hline
\end{tabular}

Since a not negligible number of patients experience angina pain after an episode of MINOCA $^{91}$, symptomatic antianginal treatment with beta-blockers, calcium channel blockers or longacting nitrates is often needed. If vasospasm is the underlying mechanism, calcium channel blockers are the most effective symptomatic therapy; nitrates represent another option. In case of reduced left-ventricular function, treatments such as ACEI or $\mathrm{ARB}$, beta-blockers and other evidence-based treatments for heart failure should be initiated in patients with MINOCA.

\section{INVASIVE TREATMENT - STENTING OF NON-OBSTRUCTIVE}

\section{CULPRIT LESIONS}

There is a paucity of data on the effectiveness of percutaneous coronary intervention (PCI) (with or without drug-eluting stents) for the treatment of culprit MINOCA lesions due to plaque ulceration or erosion. For this reason, dedicated working groups have not encouraged PCI of MINOCA lesions ${ }^{4,5}$.

In a pilot study, Prati et al compared the effectiveness of medical (DAPT) versus angioplasty and stenting in 31 patients with OCT-detected culprit plaque erosion ${ }^{92}$. At a median follow-up of 753 days, all patients were asymptomatic. This study was the first to suggest an alternative treatment strategy for patients with acute coronary events and non-obstructive lesions. The EROSION study confirmed this finding. Medical treatment with DAPT, and without PCI, led to an acceptable one-year revascularisation rate of $5.7 \%{ }^{93}$. 
In an OCT study, Imola et al evaluated the role of stent positioning for the treatment of ambiguous/intermediate lesions in 40 patients $^{94}$. Drug-eluting stent treatment was performed per protocol in the presence of local thrombosis due to ulceration or erosion. Over a mean period of $4.6 \pm 3.2$ months, no deaths, acute myocardial infarctions or stent thromboses were reported.

Variant angina is a diffuse coronary disease that tends to occur at different coronary sites. PCI with stenting should not be performed for vasospastic angina without severe organic stenosis ${ }^{95}$. However, stenting represents a feasible treatment for patients with vasospastic angina refractory to medical therapy ${ }^{95-97}$.

\section{TREATMENT OF SCAD}

In the presence of SCAD, stenting is associated with an increased risk of complications ${ }^{50,64,68,70}$, as it may propagate the vessel dissection upstream and downstream. Therefore, a conservative approach without angioplasty is recommended in the majority of patients. PCI is suggested only in the presence of highrisk anatomical features including severe proximal locations in the left main artery and left anterior descending artery, low Thrombolysis In Myocardial Infarction (TIMI) grade, or ongoing ischaemia with haemodynamic instability ${ }^{51,98}$. The difficulties inherent to the procedures, the presence of a healing process, and the frequent distal location of SCAD support this approach. Several different strategies have been utilised for PCI treatment of SCAD although there are no head-to-head studies to prove the superiority of one approach over the others. Positioning of current-generation drug-eluting stents is a common technical solution. In the absence of overlying atherosclerotic plaques, the use of bioabsorbable scaffolds seems an appealing technique ${ }^{99}$. Dilatation with cutting balloons (with or without stenting) can be a reasonable option to fenestrate the intramural haematoma and enlarge the true vessel lumen ${ }^{100}$.

Coronary artery bypass grafting (CABG) does not represent an appropriate solution in most patients with SCAD. In fact, the longterm patency of bypass grafts is poor due to the frequent healing of grafted arteries, which may lead to competitive flow and subsequent graft occlusion ${ }^{68}$.

Long-term treatment with beta-blockers is a reasonable option ${ }^{98}$. Data from a large cohort showed a lower risk of recurrences in SCAD survivors taking beta-blockers ${ }^{55}$. The adoption of lipid-lowering therapies does not seem to have much rationale for a clinical condition unrelated to cholesterol deposition. Retrospective data from the Mayo Clinic group even suggest a slightly higher risk of recurrence in patients taking statins ${ }^{70}$. Since thrombus does not seem to have a major role in the pathophysiology of SCAD ${ }^{67,72}$, the use of antiplatelet therapies remains controversial. There is a tradeoff between the treatment of any existing luminal thrombosis and the risk of an extension of intramural dissection due to intramural bleeding. Based on an expert consensus, DAPT may be considered during the acute phase of SCAD and for up to one year for patients who did not undergo $\mathrm{PCI}^{53}$. Aspirin may be effective for prevention of thrombotic complications in patients with fibromuscular dysplasia but should be avoided in patients at risk of bleeding.

\section{Conclusions and future areas of research}

Knowledge of the incidence, risk factors and prognosis of MINOCA, as well as of underlying pathophysiological mechanisms, has developed significantly over the last decade. Noninvasive imaging, particularly CT scanning, may in the future become a frontline gatekeeper for non-invasive diagnosis of MINOCA. However, improved accuracy of CT will be required for the diagnosis of complicated plaques with thrombi. The application of software for the automated interpretation of intracoronary imaging modalities, especially OCT, may represent a further option to improve the diagnosis of MINOCA in routine care.

There are still fundamental gaps in our knowledge of this heterogeneous entity. The interpretation of the research literature is hampered by the different definitions of MINOCA used, the often small and selected study populations, lack of appropriate comparison populations, and adequately sized randomised clinical trials. Properly designed prospective studies are needed to gain more insight into the pathophysiology of MINOCA and into the effectiveness of medical therapies in the different pathophysiological facets of MINOCA.

\section{Conflict of interest statement}

The authors have no conflicts of interest to declare.

\section{References}

1. Savran SV, Bryson AL, Welch TG, Zaret BL, McGowan RL, Flamm MD Jr. Clinical correlates of coronary cineangiography in young males with myocardial infarction. $\mathrm{Am}$ Heart J. 1976;91:551-5.

2. Thygesen K, Alpert JS, Jaffe AS, Chaitman BR, Bax JJ, Morrow DA, White HD; Executive Group on behalf of the Joint European Society of Cardiology (ESC) American College of Cardiology (ACC)/American Heart Association (AHA)/World Heart Federation (WHF) Task Force for the Universal Definition of Myocardial Infarction. Fourth Universal Definition of Myocardial Infarction (2018). J Am Coll Cardiol. 2018;72:2231-64.

3. Robbins SL, Bentov I. The kinetics of viscous flow in a model vessel. Effect of stenoses of varying size, shape, and length. Lab Invest.1967;16:864-74.

4. Tamis-Holland JE, Jneid H, Reynolds HR, Agewall S, Brilakis ES, Brown TM, Lerman A, Cushman M, Kumbhani DJ, Arslanian-Engoren C, Bolger AF, Beltrame JF; American Heart Association Interventional Cardiovascular Care Committee of the Council on Clinical Cardiology; Council on Cardiovascular and Stroke Nursing; Council on Epidemiology and Prevention; and Council on Quality of Care and Outcomes Research. Contemporary Diagnosis and Management of Patients With Myocardial Infarction in the Absence of Obstructive Coronary Artery Disease: A Scientific Statement From the American Heart Association. Circulation. 2019; 139:e891-908.

5. Agewall S, Beltrame JF, Reynolds HR, Niessner A, Rosano G, Caforio AL, De Caterina R, Zimarino M, Roffi M, Kjeldsen K, Atar D, Kaski JC, Sechtem U, Tornvall P; WG on Cardiovascular Pharmacotherapy. ESC working group position paper on myocardial infarction with non-obstructive coronary arteries. Eur Heart J. 2017;38:143-53.

6. Pasupathy S, Air T, Dreyer RP, Tavella R, Beltrame JF. Systematic review of patients presenting with suspected myocardial infarction and nonobstructive coronary arteries. Circulation. 2015;131:861-70.

7. Eggers KM, Hjort M, Baron T, Jernberg T, Nordenskjöld AM, Tornvall P, Lindahl B. Morbidity and cause-specific mortality in first-time myocardial infarction with nonobstructive coronary arteries. J Intern Med. 2019;285:419-28.

8. Pelliccia F, Pasceri V, Niccoli G, Tanzilli G, Speciale G, Gaudio C, Crea F, Camici PG. Predictors of Mortality in Myocardial Infarction and Nonobstructed Coronary Arteries: A Systematic Review and Meta-Regression. Am J Med. 2020; 133:73-83.

9. Nordenskjöld AM, Lagerqvist B, Baron T, Jernberg T, Hadziosmanovic N, Reynolds HR, Tornvall P, Lindahl B. Reinfarction in Patients with Myocardia Infarction with Nonobstructive Coronary Arteries (MINOCA): Coronary Findings and Prognosis. Am J Med. 2019;132:335-46. 
10. Hjort M, Lindahl B, Baron T, Jernberg T, Tornvall P, Eggers KM. Prognosis in relation to high-sensitivity cardiac troponin $\mathrm{T}$ levels in patients with myocardial infarction and non-obstructive coronary arteries. Am Heart J. 2018;200:60-6.

11. Collste O, Sörensson P, Frick M, Agewall S, Daniel M, Henareh L, Ekenbäck C, Eurenius L, Guiron C, Jernberg T, Hofman-Bang C, Malmqvist K, Nagy E, Arheden H, Tornvall P. Myocardial infarction with normal coronary arteries is common and associated with normal findings on cardiovascular magnetic resonance imaging: results from the Stockholm Myocardial Infarction with Normal Coronaries study. $J$ Intern Med. 2013;273:189-96.

12. Gerbaud E, Arabucki F, Nivet H, Barbey C, Cetran L, Chassaing S, Seguy B, Lesimple A, Cochet H, Montaudon M, Laurent F, Bar O, Tearney GJ, Coste P. OCT and CMR for the Diagnosis of Patients Presenting With MINOCA and Suspected Epicardial Causes. JACC Cardiovasc Imaging. 2020;13:2619-31.

13. Christiansen JP, Edwards C, Sinclair T, Armstrong G, Scott A, Patel H, Hart H. Detection of myocardial scar by contrast-enhanced cardiac magnetic resonance imaging in patients with troponin-positive chest pain and minimal angiographic coronary artery disease. Am J Cardiol. 2006;97:768-71.

14. Dastidar AG, Baritussio A, De Garate E, Drobni Z, Biglino G, Singhal P, Milano EG, Angelini GD, Dorman S, Strange J, Johnson T, Bucciarelli-Ducci C. Prognostic Role of CMR and Conventional Risk Factors in Myocardial Infarction With Nonobstructed Coronary Arteries. JACC Cardiovasc Imaging. 2019;12:1973-82.

15. Bhatia S, Anstine C, Jaffe AS, Gersh BJ, Chandrasekaran K, Foley TA, Hodge D, Anavekar NS. Cardiac magnetic resonance in patients with elevated troponin and normal coronary angiography. Heart. 2019;105:1231-6.

16. Mahmoudi M, Harden S, Abid N, Peebles C, Nicholas Z, Jones T, McKenzie D, Curzen N. Troponin-positive chest pain with unobstructed coronary arteries: definitive differential diagnosis using cardiac MRI. Br J Radiol. 2012;85:e461-6.

17. Kramer CM, Barkhausen J, Bucciarelli-Ducci C, Flamm SD, Kim RJ, Nagel E. Standardized cardiovascular magnetic resonance imaging (CMR) protocols: 2020 update. $J$ Cardiovasc Magn Reson. 2020;22:17.

18. Marjot J, Kaier TE, Martin ED, Reji SS, Copeland O, Iqbal M, Goodson B, Hamren S, Harding SE, Marber MS. Quantifying the Release of Biomarkers of Myocardial Necrosis from Cardiac Myocytes and Intact Myocardium. Clin Chem. 2017;63:990-6.

19. Ferreira VM, Schulz-Menger J, Holmvang G, Kramer CM, Carbone I, Sechtem U, Kindermann I, Gutberlet M, Cooper LT, Liu P, Friedrich MG. Cardiovascular Magnetic Resonance in Nonischemic Myocardial Inflammation: Expert Recommendations. J Am Coll Cardiol. 2018;72:3158-76.

20. Cundari G, Galea N, De Rubeis G, Frustaci A, Cilia F, Mancuso G, Marchitelli L, Catapano F, Carbone I, Catalano C, Francone M. Use of the new Lake Louise Criteria improves CMR detection of atypical forms of acute myocarditis. Int $J$ Cardiovasc Imaging. 2021;37:1395-404.

21. Lintingre PF, Nivet H, Clément-Guinaudeau S, Camaioni C, Sridi S, Corneloup O, Gerbaud E, Coste P, Dournes G, Latrabe V, Laurent F, Montaudon M, Cochet H. HighResolution Late Gadolinium Enhancement Magnetic Resonance for the Diagnosis of Myocardial Infarction With Nonobstructed Coronary Arteries. JACC Cardiovasc Imaging. 2020;13:1135-48.

22. Dastidar AG, Rodrigues JCL, Johnson TW, De Garate E, Singhal P, Baritussio A, Scatteia A, Strange J, Nightingale AK, Angelini GD, Baumbach A, Delgado V, Bucciarelli-Ducci C. Myocardial Infarction With Nonobstructed Coronary Arteries: Impact of CMR Early After Presentation. JACC Cardiovasc Imaging. 2017;10: 1204-6.

23. Monney PA, Sekhri N, Burchell T, Knight C, Davies C, Deaner A, Sheaf M, Baithun S, Petersen S, Wragg A, Jain A, Westwood M, Mills P, Mathur A, Mohiddin SA. Acute myocarditis presenting as acute coronary syndrome: role of early cardiac magnetic resonance in its diagnosis. Heart. 2011;97:1312-8.

24. Ambrose JA, Tannenbaum MA, Alexopoulos D, Hjemdahl-Monsen CE, Leavy J, Weiss M, Borrico S, Gorlin R, Fuster V. Angiographic progression of coronary artery disease and the development of myocardial infarction. J Am Coll Cardiol. 1988;12: $56-62$.

25. Toth GG, Toth B, Johnson NP, De Vroey F, Di Serafino L, Pyxaras S, Rusinaru D, Di Gioia G, Pellicano M, Barbato E, Van Mieghem C, Heyndrickx GR, De Bruyne B, Wijns W. Revascularization decisions in patients with stable angina and intermediate lesions: results of the international survey on interventional strategy. Circ Cardiovasc Interv. 2014;7:751-9.

26. Gould KL, Johnson NP, Bateman TM, Beanlands RS, Bengel FM, Bober R, Camici PG, Cerqueira MD, Chow BJW, Di Carli MF, Dorbala S, Gewirtz H, Gropler RJ, Kaufmann PA, Knaapen P, Knuuti J, Merhige ME, Rentrop KP, Ruddy TD, Schelbert HR, Schindler TH, Schwaiger M, Sdringola S, Vitarello J, Williams KA Sr, Gordon D, Dilsizian V, Narula J. Anatomic versus physiologic assessment of coronary artery disease. Role of coronary flow reserve, fractional flow reserve, and positron emission tomography imaging in revascularization decision-making. $J$ Am Coll Cardiol. 2013;62:1639-53.
27. Johnson TW, Räber L, di Mario C, Bourantas C, Jia H, Mattesini A, Gonzalo N, de la Torre Hernandez JM, Prati F, Koskinas K, Joner M, Radu MD, Erlinge D, Regar E, Kunadian V, Maehara A, Byrne RA, Capodanno D, Akasaka T, Wijns W, Mintz GS, Guagliumi G. Clinical use of intracoronary imaging. Part 2: acute coronary syndromes, ambiguous coronary angiography findings, and guiding interventional decision-making: an expert consensus document of the European Association of Percutaneous Cardiovascular Interventions. Eur Heart J. 2019;40:2566-84.

28. Saw J, Aymong E, Mancini GB, Sedlak T, Starovoytov A, Ricci D. Nonatherosclerotic coronary artery disease in young women. Can J Cardiol. 2014;30:814-9.

29. Beltrame JF, Crea F, Kaski JC, Ogawa H, Ong P, Sechtem U, Shimokawa H, Bairey Merz CN; Coronary Vasomotion Disorders International Study Group (COVADIS). International standardization of diagnostic criteria for vasospastic angina. Eur Heart $J$. 2017;38:2565-8.

30. Ong P, Camici PG, Beltrame JF, Crea F, Shimokawa H, Sechtem U, Kaski JC, Bairey Merz CN; Coronary Vasomotion Disorders International Study Group (COVADIS). International standardization of diagnostic criteria for microvascular angina. Int J Cardiol. 2018;250:16-20

31. Scalone G, Niccoli G, Crea F. Editor's Choice- Pathophysiology, diagnosis and management of MINOCA: an update. Eur Heart J Acute Cardiovasc Care. 2019;8: $54-62$.

32. Pirozzolo G, Seitz A, Athanasiadis A, Bekeredjian R, Sechtem U, Ong P. Microvascular spasm in non-ST-segment elevation myocardial infarction without culprit lesion (MINOCA). Clin Res Cardiol. 2020;109:246-54

33. Montone RA, Niccoli G, Fracassi F, Russo M, Gurgoglione F, Cammà G, Lanza GA, Crea F. Patients with acute myocardial infarction and non-obstructive coronary arteries: safety and prognostic relevance of invasive coronary provocative tests. Eur Heart J. 2018;39:91-8.

34. Reynolds HR, Maehara A, Kwong RY, Sedlak T, Saw J, Smilowitz NR, Mahmud E, Wei J, Marzo K, Matsumura M, Seno A, Hausvater A, Giesler C, Jhalani N, Toma C, Har B, Thomas D, Mehta LS, Trost J, Mehta PK, Ahmed B, Bainey KR, Xia Y, Shah B, Attubato M, Bangalore S, Razzouk L, Ali ZA, Merz NB, Park K, Hada E, Zhong H, Hochman JS. Coronary Optical Coherence Tomography and Cardiac Magnetic Resonance Imaging to Determine Underlying Causes of Myocardial Infarction With Nonobstructive Coronary Arteries in Women. Circulation. 2021;143:624-40.

35. Baron T, Hambraeus K, Sundstrom J, Erlinge D, Jernberg T, Lindahl B; TOTALAMI study group. Impact on Long-Term Mortality of Presence of Obstructive Coronary Artery Disease and Classification of Myocardial Infarction. $\mathrm{Am} \mathrm{J} \mathrm{Med}$. 2016;129:398-406.

36. Sandoval Y, Thygesen K. Myocardial Infarction Type 2 and Myocardial Injury. Clin Chem. 2017;63:101-7.

37. Prati F, Regar E, Mintz GS, Arbustini E, Di Mario C, Jang IK, Akasaka T, Costa M, Guagliumi G, Grube E, Ozaki Y, Pinto F, Serruys PW; Expert's OCT Review Document. Expert review document on methodology, terminology, and clinical applications of optical coherence tomography: physical principles, methodology of image acquisition, and clinical application for assessment of coronary arteries and atherosclerosis. Eur Heart J. 2010;31:401-15.

38. Souteyrand G, Amabile N, Combaret N, Hammas S, Prati F, Berry C, Pereira B, Lusson JR, Caussin C, Motreff P. Invasive management without stents in selected acute coronary syndrome patients with a large thrombus burden: a prospective study of optical coherence tomography guided treatment decisions. EuroIntervention. 2015;11: 895-904

39. Fujii K, Kobayashi Y, Mintz GS, Takebayashi H, Dangas G, Moussa I, Mehran R, Lansky AJ, Kreps E, Collins M, Colombo A, Stone GW, Leon MB, Moses JW. Intravascular ultrasound assessment of ulcerated ruptured plaques: a comparison of culprit and nonculprit lesions of patients with acute coronary syndromes and lesions in patients without acute coronary syndromes. Circulation. 2003;108:2473-8.

40. Kubo T, Imanishi T, Takarada S, Kuroi A, Ueno S, Yamano T, Tanimoto T, Matsuo Y, Masho T, Kitabata H, Tsuda K, Tomobuchi Y, Akasaka T. Assessment of culprit lesion morphology in acute myocardial infarction: ability of optical coherence tomography compared with intravascular ultrasound and coronary angioscopy. $J \mathrm{Am}$ Coll Cardiol. 2007;50:933-9.

41. Barr PR, Harrison W, Smyth D, Flynn C, Lee M, Kerr AJ. Myocardial Infarction Without Obstructive Coronary Artery Disease is Not a Benign Condition (ANZACS-QI 10). Heart Lung Circ. 2018;27:165-74.

42. Mintz GS. Predicting the Vulnerable Patient Using Intravascular Imaging. $J$ Am Coll Cardiol. 2017;69:2514-6.

43. Prati F, Gatto L, Romagnoli E, Limbruno U, Fineschi M, Marco V, Albertucci M, Tamburino C, Crea F, Alfonso F, Arbustini E. In vivo vulnerability grading system of plaques causing acute coronary syndromes: An intravascular imaging study. Int $J$ Cardiol. 2018;269:350-5.

44. Pu J, Mintz GS, Brilakis ES, Banerjee S, Abdel-Karim AR, Maini B, Biro S, Lee JB, Stone GW, Weisz G, Maehara A. In vivo characterization of coronary plaques: 
novel findings from comparing greyscale and virtual histology intravascular ultrasound and near-infrared spectroscopy. Eur Heart J. 2012;33:372-83.

45. Reynolds HR, Srichai MB, Iqbal SN, Slater JN, Mancini GB, Feit F, Pena-Sing I, Axel L, Attubato MJ, Yatskar L, Kalhorn RT, Wood DA, Lobach IV, Hochman JS Mechanisms of myocardial infarction in women without angiographically obstructive coronary artery disease. Circulation. 2011;124:1414-25.

46. Hong MK, Mintz GS, Lee CW, Lee BK, Yang TH, Kim YH, Song JM, Han KH, Kang DH, Cheong SS, Song JK, Kim JJ, Park SW, Park SJ. The site of plaque rupture in native coronary arteries: a three-vessel intravascular ultrasound analysis. $\mathrm{J} \mathrm{Am} \mathrm{Coll}$ Cardiol. 2005;46:261-5.

47. Opolski MP, Spiewak M, Marczak M, Debski A, Knaapen P, Schumacher SP, Staruch AD, Grodecki K, Chmielak Z, Lazarczyk H, Kukula K, Tyczynski P, Pregowski J, Dabrowski M, Kadziela J, Florczak E, Skrobisz A, Witkowski A. Mechanisms of Myocardial Infarction in Patients With Nonobstructive Coronary Artery Disease: Results From the Optical Coherence Tomography Study. JACC Cardiovasc Imaging. 2019;12:2210-21.

48. Taruya A, Tanaka A, Nishiguchi T, Ozaki Y, Kashiwagi M, Yamano T, Matsuo Y, Ino Y, Kitabata H, Takemoto K, Kubo T, Hozumi T, Akasaka T. Lesion characteristics and prognosis of acute coronary syndrome without angiographically significant coronary artery stenosis. Eur Heart J Cardiovasc Imaging. 2019;21:202-9.

49. Prati F, Romagnoli E, Gatto L, La Manna A, Burzotta F, Ozaki Y, Marco V, Boi A, Fineschi M, Fabbiocchi F, Taglieri N, Niccoli G, Trani C, Versaci F, Calligaris G, Ruscica G, Di Giorgio A, Vergallo R, Albertucci M, Biondi-Zoccai G, Tamburino C, Crea F, Alfonso F, Arbustini E. Relationship between coronary plaque morphology of the left anterior descending artery and 12 months clinical outcome: the CLIMA study. Eur Heart J. 2020;41:383-91.

50. Saw J, Aymong E, Sedlak T, Buller CE, Starovoytov A, Ricci D, Robinson S, Vuurmans T, Gao M, Humphries K, Mancini GB. Spontaneous coronary artery dissection: association with predisposing arteriopathies and precipitating stressors and cardiovascular outcomes. Circ Cardiovasc Interv. 2014;7:645-55.

51. Saw J, Mancini GBJ, Humphries KH. Contemporary Review on Spontaneous Coronary Artery Dissection. J Am Coll Cardiol. 2016;68:297-312.

52. Elkayam U, Jalnapurkar S, Barakkat MN, Khatri N, Kealey AJ, Mehra A, Roth A. Pregnancy-associated acute myocardial infarction: a review of contemporary experience in 150 cases between 2006 and 2011. Circulation. 2014;129:1695-702.

53. Tweet MS, Hayes SN, Codsi E, Gulati R, Rose CH, Best PJM. Spontaneous Coronary Artery Dissection Associated With Pregnancy. J Am Coll Cardiol. 2017; 70:426-35.

54. Prasad M, Tweet MS, Hayes SN, Leng S, Liang JJ, Eleid MF, Gulati R, Vrtiska TJ. Prevalence of extracoronary vascular abnormalities and fibromuscular dysplasia in patients with spontaneous coronary artery dissection. Am J Cardiol. 2015;115:1672-7. 55. Saw J, Humphries K, Aymong E, Sedlak T, Prakash R, Starovoytov A, Mancini GBJ. Spontaneous Coronary Artery Dissection: Clinical Outcomes and Risk of Recurrence. J Am Coll Cardiol. 2017;70:1148-58.

56. Saw J, Starovoytov A, Humphries K, Sheth T, So D, Minhas K, Brass N, Lavoie A, Bishop H, Lavi S, Pearce C, Renner S, Madan M, Welsh RC, Lutchmedial S, Vijayaraghavan R, Aymong E, Har B, Ibrahim R, Gornik HL, Ganesh S, Buller C, Matteau A, Martucci G, Ko D, Mancini GBJ. Canadian spontaneous coronary artery dissection cohort study: in-hospital and 30-day outcomes. Eur Heart J. 2019;40: 1188-97.

57. Lie JT, Berg KK. Isolated fibromuscular dysplasia of the coronary arteries with spontaneous dissection and myocardial infarction. Hum Pathol. 1987;18:654-6.

58. Sato C, Wakabayashi K, Suzuki H. Natural course of isolated spontaneous coronary artery dissection in Marfan syndrome. Int J Cardiol. 2014;177:20-2.

59. Aldoboni AH, Hamza EA, Majdi K, Ngibzadhe M, Palasaidi S, Moayed DA. Spontaneous dissection of coronary artery treated by primary stenting as the first presentation of systemic lupus erythematosus. J Invasive Cardiol. 2002;14:694-6.

60. Anuwatworn A, Sethi P, Steffen K, Jonsson O, Petrasko M. Spontaneous Coronary Artery Dissection: A Rare Manifestation of Alport Syndrome. Case Rep Cardiol. 2017;2017:1705927.

61. Nakamura M, Yajima J, Oikawa Y, Ogasawara K, Uejima T, Abe K, Aizawa T. Vascular Ehlers-Danlos syndrome--all three coronary artery spontaneous dissections. J Cardiol. 2009;53:458-62.

62. Nizamuddin SL, Broderick DK, Minehart RD, Kamdar BB. Spontaneous coronary artery dissection in a parturient with Nail-Patella syndrome. Int J Obstet Anesth. 2015;24:69-73.

63. Kothari D, Ruygrok P, Gentles T, Occleshaw C. Spontaneous coronary artery dissection in an adolescent man with systemic lupus erythematosus. Intern Med J. 2007;37:342-3

64. Nakashima T, Noguchi T, Haruta S, Yamamoto Y, Oshima S, Nakao K, Taniguchi Y, Yamaguchi J, Tsuchihashi K, Seki A, Kawasaki T, Uchida T, Omura N, Kikuchi M, Kimura K, Ogawa H, Miyazaki S, Yasuda S. Prognostic impact of spontaneous coronary artery dissection in young female patients with acute myocardial infarction: A report from the Angina Pectoris-Myocardial Infarction Multicenter Investigators in Japan. Int J Cardiol. 2016;207:341-8.

65. Maehara A, Mintz GS, Castagna MT, Pichard AD, Satler LF, Waksman R, Suddath WO, Kent KM, Weissman NJ. Intravascular ultrasound assessment of spontaneous coronary artery dissection. Am J Cardiol. 2002;89:466-8.

66. Paulo M, Sandoval J, Lennie V, Dutary J, Medina M, Gonzalo N, JimenezQuevedo P, Escaned J, Bañuelos C, Hernandez R, Macaya C, Alfonso F. Combined use of OCT and IVUS in spontaneous coronary artery dissection. JACC Cardiovasc Imaging. 2013;6:830-2.

67. Alfonso F, Paulo M, Gonzalo N, Dutary J, Jimenez-Quevedo P, Lennie V, Escaned J, Bañuelos C, Hernandez R, Macaya C. Diagnosis of spontaneous coronary artery dissection by optical coherence tomography. J Am Coll Cardiol. 2012;59:1073-9.

68. Tweet MS, Eleid MF, Best PJ, Lennon RJ, Lerman A, Rihal CS, Holmes DR Jr, Hayes SN, Gulati R. Spontaneous coronary artery dissection: revascularization versus conservative therapy. Circ Cardiovasc Interv. 2014;7:777-86.

69. Hassan S, Prakash R, Starovoytov A, Saw J. Natural History of Spontaneous Coronary Artery Dissection With Spontaneous Angiographic Healing. JACC Cardiovasc Interv. 2019;12:518-27.

70. Tweet MS, Hayes SN, Pitta SR, Simari RD, Lerman A, Lennon RJ, Gersh BJ, Khambatta S, Best PJ, Rihal CS, Gulati R. Clinical features, management, and prognosis of spontaneous coronary artery dissection. Circulation. 2012;126:579-88.

71. Eleid MF, Tweet MS, Young PM, Williamson E, Hayes SN, Gulati R. Spontaneous coronary artery dissection: challenges of coronary computed tomography angiography. Eur Heart J Acute Cardiovasc Care. 2018;7:609-13.

72. Jackson R, Al-Hussaini A, Joseph S, van Soest G, Wood A, Macaya F, Gonzalo N, Cade J, Caixeta A, Hlinomaz O, Leinveber P, O'Kane P, García-Guimaraes M, Cortese B, Samani NJ, Escaned J, Alfonso F, Johnson T, Adlam D. Spontaneous Coronary Artery Dissection: Pathophysiological Insights From Optical Coherence Tomography. JACC Cardiovasc Imaging. 2019;12:2475-88.

73. Liang JJ, Prasad M, Tweet MS, Hayes SN, Gulati R, Breen JF, Leng S, Vrtiska TJ A novel application of CT angiography to detect extracoronary vascular abnormalities in patients with spontaneous coronary artery dissection. $J$ Cardiovasc Comput Tomogr. 2014;8:189-97.

74. Olin JW, Froehlich J, Gu X, Bacharach JM, Eagle K, Gray BH, Jaff MR, Kim ES, Mace P, Matsumoto AH, McBane RD, Kline-Rogers E, White CJ, Gornik HL. The United States Registry for Fibromuscular Dysplasia: results in the first 447 patients. Circulation. 2012;125:3182-90.

75. Olin JW, Gornik HL, Bacharach JM, Biller J, Fine LJ, Gray BH, Gray WA, Gupta R, Hamburg NM, Katzen BT, Lookstein RA, Lumsden AB, Newburger JW, Rundek T, Sperati CJ, Stanley JC; American Heart Association Council on Peripheral Vascular Disease; American Heart Association Council on Clinical Cardiology; American Heart Association Council on Cardiopulmonary, Critical Care, Perioperative and Resuscitation; American Heart Association Council on Cardiovascular Disease in the Young; American Heart Association Council on Cardiovascular Radiology and Intervention; American Heart Association Council on Epidemiology and Prevention; American Heart Association Council on Functional Genomics and Translational Biology; American Heart Association Council for High Blood Pressure Research; American Heart Association Council on the Kidney in Cardiovascular Disease; American Heart Association Stroke Council. Fibromuscular dysplasia: state of the science and critical unanswered questions: a scientific statement from the American Heart Association. Circulation. 2014;129:1048-78.

76. Safdar B, D'Onofrio G, Dziura J, Russell RR, Johnson C, Sinusas AJ. Prevalence and characteristics of coronary microvascular dysfunction among chest pain patients in the emergency department. Eur Heart J Acute Cardiovasc Care. 2020;9:5-13.

77. Bairey Merz CN, Pepine CJ, Walsh MN, Fleg JL. Ischemia and No Obstructive Coronary Artery Disease (INOCA): Developing Evidence-Based Therapies and Research Agenda for the Next Decade. Circulation. 2017;135:1075-92.

78. Mauricio R, Srichai MB, Axel L, Hochman JS, Reynolds HR. Stress Cardiac MRI in Women With Myocardial Infarction and Nonobstructive Coronary Artery Disease. Clin Cardiol. 2016;39:596-602.

79. Dilsizian V, Bacharach SL, Beanlands RS, Bergmann SR, Delbeke D, Dorbala S, Gropler RJ, Knuuti J, Schelbert HR, Travin MI. ASNC imaging guidelines/SNMMI procedure standard for positron emission tomography (PET) nuclear cardiology procedures. J Nucl Cardiol. 2016;23:1187-226.

80. Feher A, Sinusas AJ. Quantitative Assessment of Coronary Microvascular Function: Dynamic Single-Photon Emission Computed Tomography, Positron Emission Tomography, Ultrasound, Computed Tomography, and Magnetic Resonance Imaging. Circ Cardiovasc Imaging. 2017;10:e006427.

81. Everaars H, van Diemen PA, Bom MJ, Schumacher SP, de Winter RW, van de Ven PM, Raijmakers PG, Lammertsma AA, Hofman MBM, van der Geest RJ, Götte MJ, van Rossum AC, Nijveldt R, Danad I, Driessen RS, Knaapen P. Comparison 
between quantitative cardiac magnetic resonance perfusion imaging and [15O]H2O positron emission tomography. Eur J Nuc Med Mol Imaging. 2020;47:1688-97.

82. Nordenskjöld AM, Agewall S, Atar D, Baron T, Beltrame J, Bergström O, Erlinge D, Gale CP, López-Pais J, Jernberg T, Johansson P, Ravn-Fisher A, Reynolds HR, Somaratne JB, Tornvall P, Lindahl B. Randomized evaluation of beta blocker and ACE-inhibitor/angiotensin receptor blocker treatment in patients with myocardial infarction with non-obstructive coronary arteries (MINOCA-BAT): Rationale and design. Am Heart J. 2021;231:96-104.

83. Lindahl B, Baron T, Erlinge D, Hadziosmanovic N, Nordenskjöld AM, Gard A, Jernberg T. Medical Therapy for Secondary Prevention and Long-Term Outcome in Patients with Myocardial Infarction with Non-Obstructive Coronary Artery Disease. Circulation. 2017;135:1481-9.

84. Kovach CP, Hebbe A, O'Donnell CI, Plomondon ME, Hess PL, Rahman A, Mulukutla S, Waldo SW, Valle JA. Comparison of Patients With Nonobstructive Coronary Artery Disease With Versus Without Myocardial Infarction (from the VA Clinical Assessment Reporting and Tracking [CART] Program). Am J Cardiol. 2021;146:1-7.

85. Abdu FA, Liu L, Mohammed AQ, Xu B, Yin G, Xu S, Xu Y, Che W. Effect of Secondary Prevention Medication on the Prognosis in Patients With Myocardial Infarction With Nonobstructive Coronary Artery Disease. J Cardiovasc Pharmacol. 2020;76:678-83.

86. Ciliberti G, Verdoia M, Merlo M, Zilio F, Vatrano M, Bianco F, Mancone M, Zaffalon D, Bonci A, Boscutti A, Infusino F, Coiro S, Stronati G, Tritto I, Gioscia R, Dello Russo A, Fedele F, Gallina S, Cassadonte F, Ambrosio G, Bonmassari R, De Luca G, Sinagra G, Capucci A, Kaski JC, Guerra F. Pharmacological therapy for the prevention of cardiovascular events in patients with myocardial infarction with nonobstructed coronary arteries (MINOCA): Insights from a multicentre national registry. Int J Cardiol. 2021;327:9-14.

87. Paolisso P, Bergamaschi L, Saturi G, D'Angelo EC, Magnani I, Toniolo S, Stefanizzi A, Rinaldi A, Bartoli L, Angeli F, Donati F, Rucci P, Mattioli AV, Taglieri N, Pizzi C, Galiè N. Secondary Prevention Medical Therapy and Outcomes in Patients With Myocardial Infarction With Non-Obstructive Coronary Artery Disease. Front Pharmacol. 2020;10:1606.

88. Bossard M, Gao P, Boden W, Steg G, Tanguay JF, Joyner C, Granger CB, Kastrati A, Faxon D, Budaj A, Pais P, Di Pasquale G, Valentin V, Flather M, Moccetti T, Yusuf S, Mehta SR. Antiplatelet therapy in patients with myocardial infarction without obstructive coronary artery disease. Heart. 2021 Jan 27. [Epub ahead of print].

89. Koskinas KC, Siontis GCM, Piccolo R, Mavridis D, Räber L, Mach F, Windecker S. Effect of statins and non-statin LDL-lowering medications on cardiovascular outcomes in secondary prevention: a meta-analysis of randomized trials. Eur Heart J. 2018;39: $1172-80$.
90. Eggers K, Hadziosmanovic N, Baron T, Hambraeus K, Jernberg T, Nordenskjöld A, Tornvall P, Lindahl B. Myocardial Infarction with Non-Obstructive Coronary Arteries - The Importance of Achieving Secondary Prevention Targets. Am J Med. 2018;131:524-31.

91. Safdar B, Spatz ES, Dreyer RP, Beltrame JF, Lichtman JH, Spertus JA, Reynolds HR, Geda M, Bueno H, Dziura JD, Krumholz HM, D'Onofrio G. Presentation, Clinical Profile, and Prognosis of Young Patients With Myocardial Infarction With Nonobstructive Coronary Arteries (MINOCA): Results From the VIRGO Study. J Am Heart Assoc. 2018;7:e009174.

92. Prati F, Uemura S, Souteyrand G, Virmani R, Motreff P, Di Vito L, BiondiZoccai G, Halperin J, Fuster V, Ozaki Y, Narula J. OCT-based diagnosis and management of STEMI associated with intact fibrous cap. JACC Cardiovasc Imaging. $2013 ; 6: 283-7$

93. Xing L, Yamamoto E, Sugiyama T, Jia H, Ma L, Hu S, Wang C, Zhu Y, Li L, Xu M, Liu H, Bryniarski K, Hou J, Zhang S, Lee H, Yu B, Jang IK. EROSION Study (Effective Anti-Thrombotic Therapy Without Stenting: Intravascular Optical Coherence Tomography-Based Management in Plaque Erosion): A 1-Year Follow-Up Report. Circ Cardiovasc Interv. 2017;10:e005860.

94. Imola F, Mallus MT, Ramazzotti V, Manzoli A, Pappalardo A, Di Giorgio A, Albertucci M, Prati F. Safety and feasibility of frequency domain optical coherence tomography to guide decision making in percutaneous coronary intervention. EuroIntervention. 2010;6:575-81.

95. JCS Joint Working Group. Guidelines for diagnosis and treatment of patients with vasospastic angina (Coronary Spastic Angina) (JCS 2013). Circ J. 2014;78:2779-801. 96. Chu G, Zhang G, Zhang Z, Liu S, Wen Q, Sun B. Clinical outcome of coronary stenting in patients with variant angina refractory to medical treatment: a consecutive single-center analysis. Med Princ Pract. 2013;22:583-7.

97. Gaspardone A, Tomai F, Versaci F, Ghini AS, Polisca P, Crea F, Chiariello L, Gioffrè PA. Coronary artery stent placement in patients with variant angina refractory to medical treatment. Am J Cardiol. 1999;84:96-8.

98. Adlam D, Alfonso F, Maas A, Vrints C; Writing Committee. European Society of Cardiology, acute cardiovascular care association, SCAD study group: a position paper on spontaneous coronary artery dissection. Eur Heart J. 2018;39:3353-68.

99. Macaya F, Salinas P, Gonzalo N, Camacho-Freire SJ, Jackson R, Massot M, OrtasNadal MR, Sánchez-Recalde Á, Díaz-Fernández JF, Moreu J, Adlam D, Escaned J. Long-term follow-up of spontaneous coronary artery dissection treated with bioresorbable scaffolds. EuroIntervention. 2019;14:1403-5.

100. Alkhouli M, Cole M, Ling FS. Coronary artery fenestration prior to stenting in spontaneous coronary artery dissection. Catheter Cardiovasc Interv. 2016;88:E23-7. 